\title{
Real - rheumatoid arthritis in real life - study cohort: a sociodemographic profile of rheumatoid arthritis in Brazil
}

Nathália de Carvalho Sacilotto ${ }^{1 *}$ (D), Rina Dalva Neubarth Giorgi ${ }^{1}$, Ana Beatriz Vargas-Santos ${ }^{2}$, Cleandro Pires de Albuquerque ${ }^{3}$, Sebastião Cezar Radominski ${ }^{4}$, Ivânio Alves Pereira ${ }^{5}$, Maria Fernanda Brandão Resende Guimarães ${ }^{6}$, Manoel Barros Bértolo ${ }^{7}$, Paulo Louzada $\mathrm{Jr}^{8}$, Maria de Fátima Lobato da Cunha Sauma ${ }^{9}$, Karina Rossi Bonfiglioli ${ }^{10}$, Claiton Viegas Brenol ${ }^{11}$, Licia Maria Henrique da Mota ${ }^{3}$ and Geraldo da Rocha Castelar-Pinheiro ${ }^{2}$

\begin{abstract}
Background: In Brazil, socioeconomic differences in the incidence of rheumatoid arthritis (RA) have been demonstrated, which are important in the formulation of hypotheses regarding the association between environmental factors, lifestyle and the risk of disease development. This study examines how the socioeconomic condition of the patient with RA in Brazil, assessed according to social class, educational level, employment situation and use of caregivers, affects the times between the beginning of symptoms and diagnosis and the beginning of the use of disease-modifying antirheumatic drugs, as well as the presence of erosive disease and functional status.
\end{abstract}

Methods: This work is part of a multicentric study called REAL - Rheumatoid Arthritis in Real Life in Brazil, which is a prospective observational cohort study.

Results: As described in the REAL study, we included a total of 1115 patients. It was noted that patients with an educational classification of up to second grade incomplete presented with erosion percentages above those with a higher grade complete. Patients with caregivers presented a higher percentage of erosion than patients without caregivers. We verified that patients from economic classes above B2 presented fewer occurrences of erosion than those from classes C2, D-E. We also analyzed the average time differences from the beginning of symptoms and diagnosis and the beginning of treatment, according to academic level, erosion and economic classification. Patients with first grade complete showed an HAQ-DI averages higher than those with second grade complete. The patients who had employment showed lower HAQ-DI averages than patients who were not employed. The patients with erosion showed an HAQ-DI value higher than those without erosion. Patients with caregivers showed an HAQ-DI average higher than that of without caregivers.

(Continued on next page)

\footnotetext{
* Correspondence: nath-cs@uol.com.br

${ }^{1}$ Hospital do ServidorPúblicoEstadual de São Paulo, Rua Pedro de Toledo,

1800, Vila Clementino, São Paulo, SP 04039-000, Brazil

Full list of author information is available at the end of the article
}

(c) The Author(s). 2020 Open Access This article is licensed under a Creative Commons Attribution 4.0 International License, which permits use, sharing, adaptation, distribution and reproduction in any medium or format, as long as you give appropriate credit to the original author(s) and the source, provide a link to the Creative Commons licence, and indicate if changes were made. The images or other third party material in this article are included in the article's Creative Commons licence, unless indicated otherwise in a credit line to the material. If material is not included in the article's Creative Commons licence and your intended use is not permitted by statutory regulation or exceeds the permitted use, you will need to obtain permission directly from the copyright holder. To view a copy of this licence, visit http://creativecommons.org/licenses/by/4.0/. 


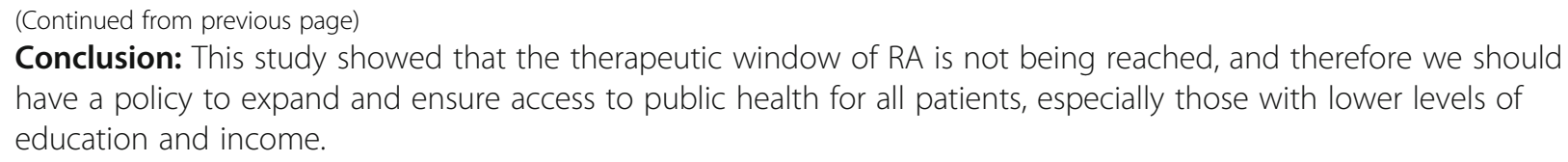

\section{Background}

Rheumatoid arthritis (RA) is an autoimmune disease associated with periods of inflammation and progressive joint damage, possibly leading to a reduction in movement and premature death [1].

Socioeconomic differences in the incidence of RA, which are important in the formulation of hypotheses regarding the association between environmental factors, lifestyle and the risk of disease development, have been demonstrated. Studies show that patients with a higher socioeconomic level have half the risk of RA development than patients with a lower level $[2,3]$, as well as a better outcome inclusively proved by a lower index in the Health Assessment Questionnaire-Disability Index (HAQ-DI) [4]. A better educational level and nonmanual work were associated with a lower risk of RA development [2].

Such socioeconomic differences are also important from the perspective of public health. It is estimated that $20-70 \%$ of patients who are employed at the beginning of an RA diagnosis are unable to continue their work activities 7-10 years into the evolution of the disease, which can have negative consequences, including a reduction in social activities, quality of life and socioeconomic conditions [5].

However, the economic impact of RA must also be assessed by the productivity of patients who continue to work that can be adversely affected by absences related to the disease or limits in working capacity, which is also important in the assessment of the functional class [6, 7]. Such limitations have shown themselves to be one of the principal economic consequences of RA and can be reduced by aggressive and early treatment during the initial phase of the disease [1].

This study examines how the socioeconomic condition of the patient with RA in Brazil, assessed according to social class, educational level, employment situation and use of caregivers, affects the time between the beginning of symptoms and diagnosis and the beginning of the use of disease-modifying antirheumatic drugs (DMARD), as well as the presence of erosive disease and functional status, as measured by the HAQ-DI.

\section{Methods}

This work is part of a Brazilian multicentric study called REAL-Rheumatoid Arthritis in Real Life in Brazil, which is a prospective observational cohort study of patients with RA from 11 public healthcare centers in different geographic regions of Brazil that are specialized in RA management. For the present article, a cross-sectional cohort was analyzed, corresponding to the initial assessment of the participants, who were accompanied afterwards for a 12-month period [8].

Each center was expected to enroll 100 patients consecutively. The inclusion criteria were as follows: 1) fulfillment of the 1987 American Rheumatism Association (ARA) or the 2010 American College of Rheumatology (ACR)/European League Against Rheumatism (EULAR) classification criteria for rheumatoid arthritis; 2) age of 18 years or older; and 3) documented medical record data of at least 6 months of follow up in their healthcare center prior to study enrollment.

All data were collected on an electronic medical chart and gathered in a centralized dataset.

We described the following characteristics: clinical, laboratory, radiographic, therapeutic and quality of life characteristics and patient adherence to treatment.

Most data were collected during the medical appointments, with previous medical records used as secondary sources. For the assessment of the clinical and demographic profiles in the present study, the following assessments were used:

- School level: divided into below literacy level, first grade not complete, first grade complete, second grade not complete, second grade complete, higher grade not complete, higher grade complete and postgraduate.

- Employment situation: divided into retired, housewife, receiving disability benefit or retired temporarily by INSS (National Social Security Institute), unemployed, unemployed looking for work in the last 3 months, formally employed worker, self-employed worker, unregistered selfemployed worker, and informally employed, completed by means of an individual questionnaire after explanations [8]. Only one option could be chosen.

- Time from symptoms to diagnosis, in months.

- Time from symptoms to first DMARD, in months.

- Economic Classification: determined by the Brazilian Economic Classification Criterion (BECC), a score 
system updated in 2015 that includes variables such as the number of household electrical appliances, level of education of the householder and access to public services [8]. The score range is stratified from A to D$E$, with each stratum corresponding to an estimated household income.

- Functional capacity assessed according to the HAQ-

DI - Health Assessment Questionnaire - Disability Index.

- The presence of erosion was documented according to the existence or lack of bone erosions in X-rays of the hands and feet. The X-rays interpretation was not standardized but individualized at each center, by certified and qualified rheumatologists.

- Necessity of caregivers.

All the patients agreed to participate in the study and signed an informed consent form.

\section{Statistical methodology}

Initially, the information was analyzed descriptively. The categorical variables were presented as absolute and relative frequencies and the numeric variables were presented as average and standard deviation for normally distributed data, and minimum, maximum, 1st quartile. Median and 3rd quartile for skewed/non-normally distributed data.

The associations between categorical variables were assessed by the Chi-squared test. To evaluate differences in distributions, we used adjusted standardized residuals, and local absolute differences were considered significant if larger than 1,96 .

For the comparison of two groups, Student's t test was used. For comparisons of more than 2 groups the nonparametric Kruskal-Wallis test was used because of the violation of the distribution normality assumption as assessed by the Kolmogorov-Smirnov test. While we used the Kruskal-Wallis test to check differences in averages, we subsequently used the multiple comparisons test of Dunn-Bonferroni to identify categories with distinct averages maintaining levels of global significance.

For all the statistical tests, we used a significance level of $5 \%$.

The statistical analyses were achieved by use of the statistics software SPSS 20.0.

\section{Results}

As described in The REAL Study, we included a total of 1115 patients with RA in Brazil. Approximately 90\% were female, with a mean age of 56.7 years and a median disease duration of 12.7 years. The majority of subjects were white, with minorities from Asian and BrazilianIndian origins making up $1 \%$ of the sample. The median BMI was $27 \mathrm{~kg} / \mathrm{m}^{2}$, with $64 \%$ of the patients classified as overweight or obese. Approximately $40 \%$ of the patients were either current or former smokers. The seropositivity rate was similar between rheumatoid factor and anticitrullinated protein antibody, but it is important to highlight that the latter was assessed in less than half of the patients, of whom only $7 \%$ were seronegative in both immunological tests. Almost half of the patients were

taking glucocorticoids, $96.5 \%$ were taking DMARDs (conventional synthetic, targeted synthetic and/or biological) of these $35.7 \%$ were taking biologics DMARDs. Of these taking biologics, $15.6 \%$ were on monotherapy. Median DAS28-ESR (Disease Activity Score 28 erythrocyte sedimentation rate) was 3.5 , with $58.7 \%$ of patients presenting moderate or high disease activity. When assessed by CDAI (Clinical Disease Activity Index), the median score represented low disease activity $(\mathrm{CDAI}=9)$, with $46.7 \%$ of subjects classified as presenting moderate to high disease activity [8].

The educational level and employment status distribution of our patients are shown in Fig. 1. Of note, among the patients who were retired, and among the patients receiving disability benefit or temporarily retired by INSS, 56 and $82 \%$, respectively, were as such due to RA. According to the BECC, patients were classified as approximately $1 \%$ in class A, $4 \%$ in class $\mathrm{B} 1,19 \%$ in class B2, $27 \%$ in class $\mathrm{C} 1,31 \%$ in class $\mathrm{C} 2$ and $18 \%$ in classes $\mathrm{D}$ and $\mathrm{E}$. Of note, $45 \%$ of patients did not present with erosive disease and 95\% did not have caregivers.

According to Table 1, we found an association between erosion and academic level $(p=0.001)$, employment situation $(p<0.001)$, use of caregivers $(p=0.042)$ and economic classification $(p<0.001)$. Accordingly, it was also noted that patients with up to a second grade incomplete education level presented erosion percentages above those with a higher grade complete. Patients with caregivers also presented a higher percentage of erosion (67.2\%) than those without a caregiver (54.2\%). Additionally, we verified that patients from economic classes B2 and higher presented fewer occurrences of erosion than those from classes C2, D-E.

According to Table 2, significant differences were found in the average time from the beginning of symptoms and diagnosis according to academic level, erosion and economic classification. We observed that the below literacy-level patients presented a higher average than patients with a higher grade complete or a postgraduate education, which were similar to each other. There were no differences in the averages between the other academic levels. In addition to this finding, patients with erosion had a longer average time from the beginning of the symptoms and diagnosis than those without erosion. Of note, the patients from classes D - E presented a longer average than the patients from classes B2 and $\mathrm{C} 1$, 


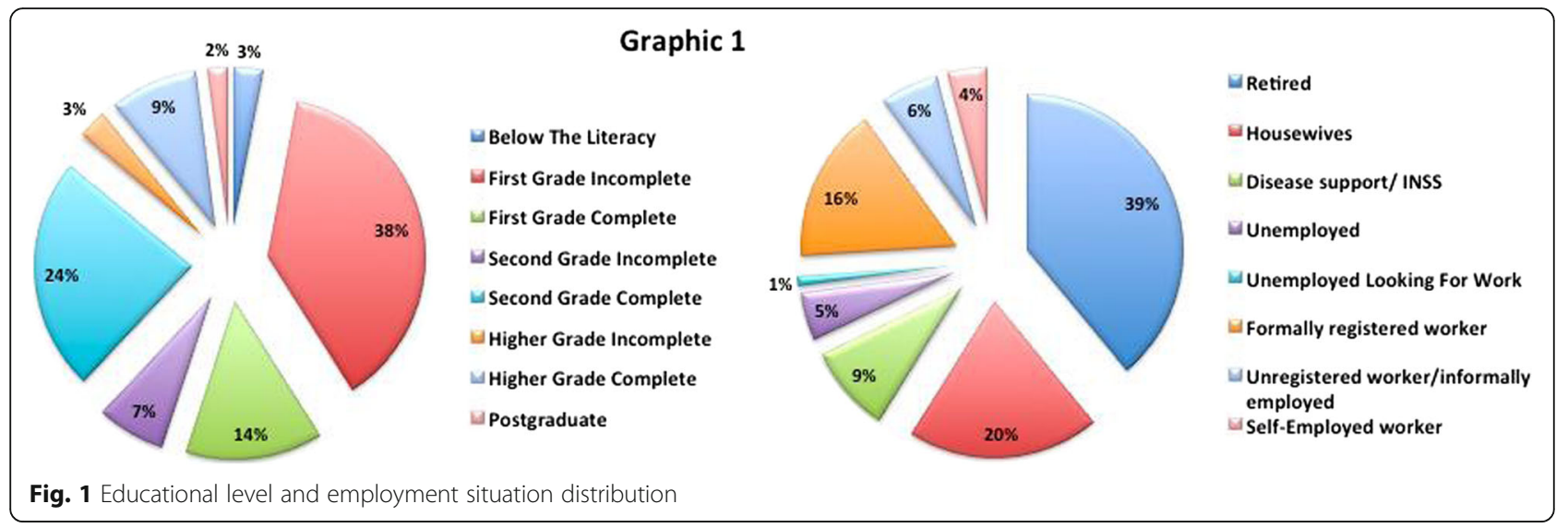

which did not differ from each other. We could not find differences in averages for the A, B1 and C2 classes from those for the others. Neither employment status nor the need of caregivers were associated with the time between symptoms and RA diagnosis.

As seen in Table 3, we found differences in average times for the beginning of treatment in terms of level of schooling, erosion and economic classification. As such, we observed that the below literacy-level patients had an average time higher than those patients with first grade complete that, in turn, presented an average higher than the patients with a higher grade complete. We did not find differences in averages in the other levels of education. In addition to this finding, patients with erosion presented a higher mean time to the beginning of the first DMARD treatment than that of patients without erosion. It was also noted that patients from the D - E classes showed a higher average than that from class $\mathrm{C} 2$

Table 1 Erosion

\begin{tabular}{|c|c|c|c|c|c|c|c|}
\hline & \multicolumn{4}{|c|}{ Erosion } & \multirow{2}{*}{\multicolumn{2}{|c|}{ Total }} & \multirow{3}{*}{ p } \\
\hline & \multicolumn{2}{|c|}{ No } & \multicolumn{2}{|c|}{ Yes } & & & \\
\hline & $\mathbf{N}$ & $\%$ & $\mathbf{N}$ & $\%$ & $\mathbf{N}$ & $\%$ & \\
\hline School grade level & 494 & $45.1 \%$ & 601 & $54.9 \%$ & 1.095 & $100 \%$ & 0.001 \\
\hline Below literacy level & 13 & $36.1 \%$ & 23 & $63.9 \%$ & 36 & $100 \%$ & \\
\hline First grade not complete & 172 & $40.6 \%$ & 252 & $59.4 \%$ & 424 & $100 \%$ & \\
\hline First grade complete & 61 & $41.2 \%$ & 87 & $58.8 \%$ & 148 & $100 \%$ & \\
\hline Second grade not complete & 26 & $35.1 \%$ & 48 & $64.9 \%$ & 74 & $100 \%$ & \\
\hline Second grade complete & 134 & $51.0 \%$ & 129 & $49.0 \%$ & 263 & $100 \%$ & \\
\hline Higher grade not complete & 15 & $50.0 \%$ & 15 & $50.0 \%$ & 30 & $100 \%$ & \\
\hline Higher grade complete & 60 & $62.5 \%$ & 36 & $37.5 \%$ & 96 & $100 \%$ & \\
\hline Postgraduate & 13 & $54.2 \%$ & 11 & $45.8 \%$ & 24 & $100 \%$ & \\
\hline Employment situation & 493 & $45.0 \%$ & 602 & $55.0 \%$ & 1.095 & $100 \%$ & $<0.001$ \\
\hline Retired & 152 & $36.4 \%$ & 266 & $63.6 \%$ & 418 & $100 \%$ & \\
\hline Receiving disability benefit or retired temporarily by INSS & 44 & $44.9 \%$ & 54 & $55.1 \%$ & 98 & $100 \%$ & \\
\hline Unemployed & 26 & $50.0 \%$ & 26 & $50.0 \%$ & 52 & $100 \%$ & \\
\hline Unemployed looking for work in the last 3 months & 3 & $37.5 \%$ & 5 & $62.5 \%$ & 8 & $100 \%$ & \\
\hline Housewife & 100 & $44.4 \%$ & 125 & $55.6 \%$ & 225 & $100 \%$ & \\
\hline Formally employed worker & 108 & $59.7 \%$ & 73 & $40.3 \%$ & 181 & $100 \%$ & \\
\hline Self-employed worker & 27 & $61.4 \%$ & 17 & $38.6 \%$ & 44 & $100 \%$ & \\
\hline Unregistered self-employed worker / informally employed & 33 & $47.8 \%$ & 36 & $52.2 \%$ & 69 & $100 \%$ & \\
\hline Caregiver & 492 & $45.1 \%$ & 600 & $54.9 \%$ & 1.092 & $100 \%$ & 0.042 \\
\hline No & 471 & $45.8 \%$ & 557 & $54.2 \%$ & 1.028 & $100 \%$ & \\
\hline Yes & 21 & $32.8 \%$ & 43 & $67.2 \%$ & 64 & $100 \%$ & \\
\hline Economic Classification & 489 & $45.1 \%$ & 595 & $54.9 \%$ & 1.084 & $100 \%$ & $<0.001$ \\
\hline A & 9 & $56.3 \%$ & 7 & $43.8 \%$ & 16 & $100 \%$ & \\
\hline B1 & 22 & $56.4 \%$ & 17 & $43.6 \%$ & 39 & $100 \%$ & \\
\hline B2 & 109 & $54.2 \%$ & 92 & $45.8 \%$ & 201 & $100 \%$ & \\
\hline $\mathrm{C} 1$ & 146 & $49.2 \%$ & 151 & $50.8 \%$ & 297 & $100 \%$ & \\
\hline $\mathrm{C} 2$ & 134 & $39.6 \%$ & 204 & $60.4 \%$ & 338 & $100 \%$ & \\
\hline$D-E$ & 69 & $35.8 \%$ & 124 & $64.2 \%$ & 193 & $100 \%$ & \\
\hline
\end{tabular}


Table 2 Time from symptoms to diagnosis, in months

\begin{tabular}{|c|c|c|c|c|c|c|c|c|c|}
\hline & Average & Standard Deviation & Minimum & Maximum & $1^{\circ}$ quartile & Median & $3^{\circ}$ quartile & $\mathbf{N}$ & $\mathbf{p}$ \\
\hline Total & 32.50 & 51.60 & 0.00 & 457 & 6.00 & 12.00 & 36.00 & 1.079 & - \\
\hline School grade level & & & & & & & & & $<0.001$ \\
\hline Below literacy level & 65.40 & 86.70 & 1.00 & 372 & 8.00 & 24.00 & 112.00 & 35 & \\
\hline First grade not complete & 33.70 & 49.90 & 0.00 & 360 & 6.00 & 12.00 & 36.00 & 414 & \\
\hline First grade complete & 35.60 & 50.00 & 0.00 & 288 & 6.00 & 12.00 & 48.00 & 148 & \\
\hline Second grade not complete & 28.10 & 43.60 & 1.00 & 256 & 6.00 & 12.00 & 24.00 & 73 & \\
\hline Second grade complete & 29.90 & 49.70 & 1.00 & 348 & 6.00 & 12.00 & 24.00 & 262 & \\
\hline Higher grade not complete & 19.70 & 32.00 & 1.00 & 145 & 4.80 & 11.5 & 19.50 & 30 & \\
\hline Higher grade complete & 29.80 & 60.70 & 1.00 & 457 & 4.00 & 12.00 & 24.00 & 94 & \\
\hline Postgraduate & 14.40 & 22.60 & 1.00 & 84 & 3.00 & 6.00 & 12.00 & 22 & \\
\hline Employment situation & & & & & & & & & 0.118 \\
\hline Retired & 37.20 & 54.80 & 0.00 & 457 & 6.00 & 12.00 & 48.00 & 415 & \\
\hline Receiving disability benefit or retired temporarily by INSS & 31.00 & 53.50 & 1.00 & 372 & 6.00 & 12.00 & 24.00 & 97 & \\
\hline Unemployed & 40.00 & 73.00 & 2.00 & 348 & 6.00 & 12.00 & 27.00 & 50 & \\
\hline Unemployed looking for work in the last 3 months & 26.30 & 34.70 & 4.00 & 108 & 7.00 & 12.00 & 33.00 & 8 & \\
\hline Housewife & 30.30 & 46.90 & 1.00 & 276 & 6.00 & 12.00 & 24.00 & 221 & \\
\hline Formally employed worker & 25.40 & 43.80 & 0.00 & 288 & 4.80 & 12.00 & 24.00 & 178 & \\
\hline Self-employed worker & 32.10 & 60.60 & 1.00 & 360 & 6.00 & 12.00 & 36.00 & 42 & \\
\hline Unregistered self-employed worker / informally employed & 27.50 & 36.00 & 1.00 & 156 & 5.00 & 12.00 & 36.00 & 67 & \\
\hline Caregiver & & & & & & & & & 0.864 \\
\hline No & 32.50 & 52.30 & 0.00 & 457 & 6.00 & 12.00 & 36.00 & 1012 & \\
\hline Sim & 33.60 & 40.20 & 1.00 & 240 & 9.00 & 24.00 & 36.00 & 63 & \\
\hline Erosão & & & & & & & & & $<0.001$ \\
\hline No & 21.50 & 30.40 & 0.00 & 240 & 6.00 & 12.00 & 24.00 & 477 & \\
\hline Yes & 41.70 & 62.90 & 0.00 & 457 & 6.00 & 12.00 & 48.00 & 584 & \\
\hline Economic Classification & & & & & & & & & 0.001 \\
\hline A & 27.40 & 35.90 & 1.00 & 120 & 6.00 & 12.00 & 42.00 & 14 & \\
\hline B1 & 29.90 & 33.50 & 1.00 & 156 & 6.00 & 12.00 & 48.00 & 38 & \\
\hline B2 & 26.40 & 48.60 & 1.00 & 457 & 5.00 & 12.00 & 24.00 & 196 & \\
\hline $\mathrm{C} 1$ & 26.00 & 37.70 & 1.00 & 269 & 6.00 & 12.00 & 24.00 & 300 & \\
\hline $\mathrm{C} 2$ & 33.80 & 53.50 & 0.00 & 348 & 6.00 & 12.00 & 30.00 & 329 & \\
\hline$D-E$ & 47.80 & 69.70 & 0.00 & 372 & 8.30 & 18.00 & 48.00 & 188 & \\
\hline
\end{tabular}

which in turn was higher than those in classes B2 and $\mathrm{C} 1$, which did not differ from each other. We did not find any differences in averages in classes A and B1 compared to those in the others. Neither employment status nor the need of caregivers were associated with the average time to the beginning of DMARD treatment.

As shown in Table 4, differences in HAQ averages were found in all demographic characteristics assessed by the study. Accordingly, we observed that patients with first grade completed showed an HAQ-DI average higher than those with second grade completed, but we could not find the difference in averages among the other levels of education. Patients receiving disability benefit from INSS or unemployed showed higher HAQ averages than those retired or unemployed looking for work in the last 3 months. The later two categories, in turn, had higher HAQ averages than the housewives. While the HAQ averages did not differ among the three categories of patients who were still working, they were lower than those from the other employment status categories. HAQ-DI averages were higher in patients with erosions than in those without them, and higher in patients who needed caregivers than in those who didn't. We also noted that patients from class $\mathrm{D} / \mathrm{E}$ showed an HAQ-DI average higher than that from class $\mathrm{C} 2$, which in turn was higher than the average of those from classes $\mathrm{C} 1, \mathrm{~B} 2$ and $\mathrm{B} 1$, which did not differ from each other. No differences were noted between the class A HAQ-DI average and the averages of the other economical classes.

\section{Discussion}

We describe a cohort of 1115 patients selected from different geographic regions of Brazil. The REAL study showed that the demographic, clinical, serological and radiographic characteristics of the patients being followed had several similar but some divergent characteristics from those of previously published North American, European and Latin American cohorts. Particularly notable was the long delay for diagnosis and the high frequency of corticosteroid use and of erosive disease as well as the elevated percentage of patients with moderate or high disease activity. The high frequency of biologic DMARD use, considering the economic limitations in Brazil, is also notable [8]. 
Table 3 Time from symptoms to first DMARD, in months

\begin{tabular}{|c|c|c|c|c|c|c|c|c|c|}
\hline & Average & Standard Deviation & Minimum & Maximum & $1^{\circ}$ quartile & Median & $3^{\circ}$ quartile & $\mathbf{N}$ & $\mathbf{p}$ \\
\hline Total & 38.6 & 62.68 & 0.00 & 624.0 & 6.00 & 12.00 & 42.00 & 995.00 & - \\
\hline School grade level & & & & & & & & & $<0.001$ \\
\hline Below literacy level & 68.27 & 85.56 & 1.00 & 360 & 11.5 & 27.00 & 116 & 33.00 & \\
\hline First grade not complete & 38.97 & 59.75 & 0.00 & 540 & 6.00 & 14.00 & 48.00 & 380.00 & \\
\hline First grade complete & 43.83 & 56.87 & 1.00 & 288 & 9.00 & 24.00 & 60.00 & 132.00 & \\
\hline Second grade not complete & 26.07 & 39.60 & 1.00 & 256 & 5.25 & 12.00 & 24.0 & 68.00 & \\
\hline Second grade complete & 39.14 & 72.51 & 0.00 & 624 & 6.00 & 12.00 & 36.00 & 246.00 & \\
\hline Higher grade not complete & 19.18 & 33.2 & 0.00 & 144 & 3.25 & 6.00 & 17.50 & 28.00 & \\
\hline Higher grade complete & 33.31 & 58.57 & 0.00 & 327 & 4.00 & 12.00 & 26.00 & 87.00 & \\
\hline Postgraduate & 35.45 & 79.12 & 1.00 & 360 & 6.00 & 10.50 & 33.00 & 20.00 & \\
\hline Employment situation & & & & & & & & & 0.077 \\
\hline Retired & 48.31 & 77.32 & 0.00 & 624 & 6.00 & 16.00 & 60.00 & 374.00 & \\
\hline Receiving disability benefit or retired temporarily by INSS & 31.57 & 46.92 & 0.00 & 256 & 6.00 & 12.00 & 36.00 & 86.00 & \\
\hline Unemployed & 43,0 & 73.00 & 2.00 & 348 & 6.00 & 12.00 & 39.00 & 50.00 & \\
\hline Unemployed looking for work in the last 3 months & 38.13 & 37.11 & 4.00 & 108 & 8.25 & 27.00 & 66.00 & 8.00 & \\
\hline Housewife & 33.33 & 51.04 & 1.00 & 360 & 6.05 & 12.00 & 36.00 & 209.00 & \\
\hline Formally employed worker & 30.79 & 50.90 & 0.00 & 327 & 5.00 & 12.00 & 30.00 & 165.00 & \\
\hline Self-employed worker & 31.62 & 48.02 & 1.00 & 269 & 7.00 & 12.00 & 36.00 & 39.00 & \\
\hline Unregistered self-employed worker / informally employec & 29.92 & 39.92 & 1.00 & 180 & 6.00 & 12.00 & 36.00 & 63.00 & \\
\hline Caregiver & & & & & & & & & 0.816 \\
\hline No & 38.53 & 63.45 & 0.00 & 624 & 6.00 & 12.00 & 39.00 & 940.00 & \\
\hline Sim & 40.63 & 49.07 & 0.00 & 240 & 8.00 & 24.00 & 54.00 & 51.00 & \\
\hline Erosão & & & & & & & & & $<0.001$ \\
\hline No & 24.84 & 38.25 & 0.00 & 360 & 6.00 & 12.00 & 24.00 & 448.00 & \\
\hline Yes & 50.8 & 76.16 & 0.00 & 624 & 6.00 & 24.00 & 60.00 & 531.00 & \\
\hline Economic Classification & & & & & & & & & $<0.001$ \\
\hline A & 27.57 & 35.75 & 1.00 & 120 & 6.00 & 12.00 & 42.00 & 14.00 & \\
\hline B1 & 33.94 & 39.75 & 1.00 & 156 & 6.00 & 12.00 & 48.00 & 35.00 & \\
\hline B2 & 29.65 & 59.93 & 0.00 & 624 & 5.00 & 12.00 & 36.00 & 179.00 & \\
\hline $\mathrm{C} 1$ & 30.75 & 46.54 & 0.00 & 360 & 6.00 & 12.00 & 36.00 & 279.00 & \\
\hline C2 & 43.03 & 70.55 & 0.00 & 540 & 8.00 & 15.00 & 45.00 & 297.00 & \\
\hline D-E & 55.07 & 76.04 & 1.00 & 444 & 12.00 & 24.00 & 63.75 & 178.00 & \\
\hline
\end{tabular}

Table $4 \mathrm{HAQ}$.

\begin{tabular}{|c|c|c|c|c|c|c|c|c|c|}
\hline & Average & Standard Deviation & Minimum & Maximum & $1^{\circ}$ quartile & Median & $3^{\circ}$ quartile & $\mathbf{N}$ & $\mathbf{p}$ \\
\hline Total & 0.94 & 0.77 & 0.00 & 3,00 & 0.25 & 0.88 & 1.50 & 1.116 & - \\
\hline School grade level & & & & & & & & & $<0.001$ \\
\hline Below literacy level & 1.19 & 0.87 & 0.00 & 2.75 & 0.28 & 1.19 & 1.88 & 36.00 & \\
\hline First grade not complete & 1.02 & 0.80 & 0.00 & 3.00 & 0.25 & 0.88 & 1.63 & 429.00 & \\
\hline First grade complete & 1.03 & 0.73 & 0.00 & 3.00 & 0.50 & 0.88 & 1.50 & 156.00 & \\
\hline Second grade not complete & 0.97 & 0.79 & 0.00 & 3.00 & 0.25 & 0.94 & 1.44 & 74.00 & \\
\hline Second grade complete & 0.80 & 0.72 & 0.00 & 2.75 & 0.25 & 0.63 & 1.25 & 266.00 & \\
\hline Higher grade not complete & 0.85 & 0.85 & 0.00 & 2.88 & 0.00 & 0.88 & 1.38 & 31.00 & \\
\hline Higher grade complete & 0.81 & 0.69 & 0.00 & 2.50 & 0.13 & 0.63 & 1.38 & 99.00 & \\
\hline Postgraduate & 0.62 & 0.67 & 0.00 & 2.75 & 0.03 & 0.50 & 0.84 & 24.00 & \\
\hline Employment situation & & & & & & & & & $<0.001$ \\
\hline Retired & 1.05 & 0.77 & 0.00 & 3.00 & 0.38 & 1.00 & 1.63 & 430.00 & \\
\hline Receiving disability benefit or retired temporarily by INSS & 1.32 & 0.75 & 0.00 & 3.00 & 0.75 & 1.25 & 1.88 & 100.00 & \\
\hline Unemployed & 1.24 & 0.82 & 0.00 & 3.00 & 0.69 & 1.13 & 1.88 & 53.00 & \\
\hline Unemployed looking for work in the last 3 months & 1.05 & 0.8 & 0.00 & 2.63 & 0.50 & 0.94 & 1.47 & 8.00 & \\
\hline Housewife & 0.88 & 0.74 & 0.00 & 2.88 & 0.25 & 0.75 & 1.38 & 227.00 & \\
\hline Formally employed worker & 0.66 & 0.7 & 0.00 & 2.75 & 0.00 & 0.50 & 1.00 & 183.00 & \\
\hline Self-employed worker & 0.57 & 0.66 & 0.00 & 2.50 & 0.00 & 0.25 & 0.81 & 45.00 & \\
\hline Unregistered self-employed worker / informally employed & 0.64 & 0.64 & 0.00 & 2.38 & 0.13 & 0.50 & 1.00 & 69.00 & \\
\hline Caregiver & & & & & & & & & $<0.001$ \\
\hline No & 0.91 & 0.75 & 0.00 & 3.00 & 0.25 & 0.75 & 1.38 & 1046.00 & \\
\hline Sim & 1.43 & 0.84 & 0.00 & 3.00 & 0.75 & 1.38 & 2.00 & 66.00 & \\
\hline Erosão & & & & & & & & & $<0.001$ \\
\hline No & 0.78 & 0.72 & 0.00 & 2.88 & 0.13 & 0.63 & 1.25 & 494.00 & \\
\hline Yes & 1.08 & 0.79 & 0.00 & 3.00 & 0.38 & 1.00 & 1.63 & 602.00 & \\
\hline Economic Classification & & & & & & & & & $<0.001$ \\
\hline A & 0.96 & 0.81 & 0.00 & 2.5 & 0.22 & 0.81 & 1.47 & 16.00 & \\
\hline B1 & 0.83 & 0.77 & 0.00 & 3.00 & 0.25 & 0.63 & 1.13 & 39.00 & \\
\hline B2 & 0.82 & 0.74 & 0.00 & 2.88 & 0.13 & 0.63 & 1.38 & 203.00 & \\
\hline $\mathrm{C} 1$ & 0.78 & 0.69 & 0.00 & 3.00 & 0.13 & 0.63 & 1.25 & 302.00 & \\
\hline C2 & 1.05 & 0.77 & 0.00 & 3.00 & 0.38 & 1.00 & 1.63 & 345.00 & \\
\hline$D-E$ & 1.12 & 0.83 & 0.00 & 3.00 & 0.38 & 1.00 & 1.88 & 197.00 & \\
\hline
\end{tabular}


Our group study showed that erosion presence, which should be considered a risk factor for higher disease severity leading to a worse overall prognosis [9], is more frequently seen in patients with a lower education level or classified in social classes C2 and D-E. It is also related to a longer time for the diagnosis and thus a delay in the beginning of treatment, which reaches an average of 41.7 and 50.8 months, respectively. Currently, there is a generalization of the concept of initial or early RA and of the existence of a window for a therapeutic opportunity, confirming the notion that early diagnosis and treatment can modify the course of the disease. Not to diagnose, or not to adequately treat a patient with very early symptoms of RA increases the risk of persistent inflammation and progressive joint damage [10], which in turn generates an important socioeconomic impact for the community.

Between January 2005 and October 2006, the QUESTRA (Quantitative Patient Questionnaires in Standard Monitoring of Patients with RA) project, which included 4363 patients from 15 countries [11], showed that at the moment of the first symptoms, the rates of employment of patients younger than 65 years varied from 57 to $100 \%$ (average $86 \%$ ) in men and from 19 to $87 \%$ (average $86 \%$ ) in women, with the highest rates being seen in countries such as Sweden, Finland, Estonia and Lithuania and the lowest rates in countries such as Turkey, Kosovo, Morocco, Greece and Egypt. In general, more than one-third of the patients cited work disability due to RA because the probability of continuing working for 2 years was $80 \%$ and for 5 years was $68 \%$, with similar patterns in countries with a high or low gross domestic product (GDP). The most significant determinant in work incapacity in all countries was the HAQ-DI [12].

An interesting result found in the QUEST-RA study suggests that, when comparing information between countries, patients from countries with a low GDP stay in work with higher levels of incapacity and disease activity than patients from countries with a high GDP [12]. Chung et al. also noted that the withdrawal of patients with RA from the workforce was greater in Finland, regardless of their clinical status, than in the United States, in order to avoid losing their health insurance and having to wait at least one year to be awarded disability payments [13].

These findings indicate that when looking at cases of RA, cultural and economic differences in societies affect work incapacity rates. The availability of biological agents led to expectations of a reduction in such rates; however, accounts of clinical group studies indicate that RA-related work disability continues to be a large problem [12, 14-16].

As such, early diagnosis and adequate therapeutic intervention with DMARDs becomes the principal objective to manage RA to significantly improve the clinical outcome and reduce joint damage [17]. The longest symptom duration allowed and the diagnosis of RA can be defined without the risk of irreversible damage varies greatly in the literature. In the context of the window of opportunity, at the beginning of the 1990s, initial RA was considered having a duration of symptoms of less than 24 months, with great emphasis on the first 12 months of clinical manifestations. At the moment, we aim to evaluate a patient with joint symptoms at the earliest opportunity possible, and the definition of the initial phase of RA includes the first weeks or months of symptoms (generally less than 12 months), highlighting the first 12 weeks of clinical manifestations as early or initial RA as being critical [10]. In Brazil, the group study shows an average of 32.5 months between the time from the onset of symptoms and the diagnosis and 38.6 months for the beginning of treatment. However, for the below literacy-level patients, this average time span extends to 65.4 months, compared with 14.4 months for those patients of postgraduate education, as well as an average of 47.8 months in patients classified as class D/ E, compared with 26.4 in those classified in class B2. Such a difference, consequently, is also found in the time to the start of treatment. This information exposes the difficulty patients, principally those from a low educational level and economic classification, have in accessing a specialist at the beginning of the disease.

All the socioeconomic variables evaluated in this study were associated with differences in HAQ-DI. It is important to observe that the lowest HAQ-DI averages were found in patients who were economically active. In the QUEST-RA project, there were some biases found in the interpretation of the HAQ-DI. It is interesting to note that Socio-demographic factors cause relevant response bias in individual items of the health assessment questionnaire, but item bias has minor effect on composite HAQs indicating its overall accuracy across sociodemographic groups [18].

We observed that patients who need a caregiver had the highest HAQ-DI average (1.43) found in the study as a whole. Measurement of physical function at one point in time cannot distinguish impairment caused by the active disease process from chronic irreversible impairment. In this way, differences in the sources of functional limitations should be considered in the interpretation of functional measures, and in their use for prediction and in cost analyses [19].

The World Health Organization (WHO) specifies a series of individual factors in the system that can influence and determine the outcomes in pathologies. These factors include access and use of health services being recognized as independent determinants and are particularly relevant for patients who have chronic diseases. 
The large differences in health as a result of the lack of access to care are often avoidable and unfair and so can be referred to as inequalities. However, the concept of equal access to care is complex and difficult to define clearly. Three principal dimensions of access can be identified, as follows: 1 - availability of care, implying a physical presence of doctors and medicine, appointment availability, geographic distribution, capacity of the system, etc.; 2 - accessibility that includes the financing of health caregivers and insurance to cover the costs; and 3- acceptability of the interposition between the provider and the patients' attitudes in relation to the engagement of health caregivers and mutual expectations [12].

The strengths of this study are to evaluate at a national level the characteristics of patients with rheumatoid arthritis, as well as to evaluate possible associations in order to alert the correct management of patients and thus reduce morbidity and mortality, for example through public health measures to aim for the therapeutic window. The limitations of this study are the lack of standardization in X-Ray erosion readings, besides the cross-sectional design, since without a proper follow-up along time, no firm causality conclusions can be drawn. It is important to say that all the sites enrolled in the study are "reference centers", and thus are unlikely to represent the broader management of RA across the country. It is probable that these patients present more severe disease, with a less favorable prognosis. REAL study was designed to be representative of the entire Brazilian population, but one center in the Northeast (representing $27.9 \%$ of population) could not participate because of delays in the Ethics Committee approval [8].

\section{Conclusion}

This study showed that the therapeutic window of RA is not being reached, and therefore we should have a policy to expand and ensure access to public health for all patients, especially those with lower levels of education and income for early diagnosis and treatment. For better disease control and consequently improve current outcomes such as reduced erosion prevalence and better quality of life for RA patients.

\section{Authors' contributions}

All authors made substantial contributions to the acquisition of data, have been involved in drafting the manuscript or revising it critically for important intellectual content, gave final approval of the version to be published and have participated sufficiently in the work to take public responsibility for appropriate portions of the content; and agreed to be accountable for all aspects of the work in ensuring that questions related to the accuracy or integrity of any part of the work are appropriately investigated and resolved.

\section{Funding}

Brazilian Society of Rheumatology. The funding body had no role in the design of the study and collection, analysis, and interpretation of data and in writing the manuscript.

\section{Availability of data and materials}

The data are not publicly available due to them containing information that could compromisse research participant privacy/consent.

\section{Ethics approval and consent to participate}

This study was approved by the National Commission of Ethics in Research (CONEP-Comissão Nacional de Ética em Pesquisa) - Ministry of Health and by the Institutional Review Board of each of the centers involved. All patients signed the informed consent form.

\section{Consent for publication}

Not aplicable.

\section{Competing interests}

Nathália de Carvalho Sacilotto: Janssen; - RinaDalva Neubarth Giorgi: UCB, Lilly, Pfizer, Janssen, Roche; - Ana Beatriz Vargas-Santos: None; - Cleandro Albuquerque: Pfizer, Abbvie, AstraZeneca, Janssen, Bristol-Myers-Squibb, Roche, Novartis and UCB; - Sebastião Radominski: None; - Manoel Barros Bertolo: Roche, Abbvie, Pfizer; - Ivânio Pereira: None; - Paulo Louzada-Junior: Bristol-Myers Squibb, UCB, Pfizer; - Maria de Fátima Cunha Sauma: None; Karina Bonfiglioli, Roche, Janssen, Pfizer,Abbvie; - Claiton Brenol:Abbvie, BMS, Janssen, Pfizer and Roche; Maria Fernanda ResendeGuimarães: None; Licia Maria Henrique Mota: Abbvie, Janssen, Pfizer, Roche and UCB; - Geraldo Castelar-Pinheiro: Abbvie, Bristol-Myers Squibb, Eli Lilly, Glaxo Smith Kline, Janssen, Pfizer, Sanofi Genzyme and Roche.

\section{Author details}

'Hospital do ServidorPúblicoEstadual de São Paulo, Rua Pedro de Toledo, 1800, Vila Clementino, São Paulo, SP 04039-000, Brazil. ${ }^{2}$ Universidade do Estado do Rio de Janeiro, Rio de Janeiro, Brazil. ${ }^{3}$ Universidade de Brasília, Federal District, Brazil. ${ }^{4}$ Universidade Federal do Paraná, Curitiba, Brazil. ${ }^{5}$ Universidade Federal de Santa Catarina, Florianópolis, Brazil. ${ }^{6}$ Universidade Federal de Minas Gerais, Belo Horizonte, Brazil. 'UniversidadeEstadual de Campinas, Campinas, Brazil. ${ }^{8}$ Universidade de São Paulo, Ribeirão Preto, Brazil. ${ }^{9}$ Universidade Federal do Pará, Belém, Brazil. ${ }^{10}$ Universidade de São Paulo, São Paulo, Brazil. "'Universidade Federal do Rio Grande do Sul, Porto Alegre, Brazil.

Received: 13 October 2018 Accepted: 17 February 2020

Published online: 14 March 2020

\section{References}

1. Filipovic I, Walker D, Forster F, Curry AS. Quantifying the economic burden of productivity loss in rheumatoid arthritis. Rheumatology. 2011;50(6):108390.

2. Bengtsson C, Nordmark B, Klareskog L, et al. Socioeconomic status and the risk of developing RA: results from the Swedish EIRA study. Ann Rheum Dis. 2005;64(11):1588-94

3. Liaoa KP, Alfredsson L, Karlsona EW. Environmental influences on risk for rheumatoid arthritis. Curr Opin Rheumatol. 2010;21(3):279-83.

4. Harrison MJ, Farragher TM, Clarke AM, et al. Association of functional outcome with both personal and area-level socioeconomic inequalities in patients with inflammatory polyarthritis. Arthritis Care Res. 2009;61(10):1297304.

5. Hoving JL, Zwieten MCB, Meer M, et al. Work participation and arthritis: a systematic overview of challenges, adaptations and opportunities for interventions. Rheumatology. 2013;52(7):1254-64.

6. Walker N, Michaud K, Wolfe F. Work limitations among working persons with rheumatoid arthritis: results, reliability, and validity of the work limitations questionnaire in 836 patients. J Rheumatol. 2005;32:1006.

7. Hazes JM, Geuskens GA, Burdorf A. Work limitations in the outcome assessment of rheumatoid arthritis. J Rheumatol. 2005;32:980.

8. Castelar-Pinheiro GR, Vargas-Santos AB, Albuquerque CP, et al. The "REAL" Study: A Nationwide Prospective Study of Rheumatoid Arthritis in Brazil. Adv Rheumatol. 2018;58(9). https://doi.org/10.1186/s42358-018-0017-9.

9. Mota LMH, Cruz BA, Brenol CV, etal. Consenso da Sociedade Brasileira de Reumatologia 2011 para o diagnóstico e avaliação inicial da artrite reumatoide. Rev Bras Reumatol 2011; 51(3): 199-219.

10. Mota LMH, Laurindo IMM, Santos Neto LL. Artrite reumatoide inicial: conceitos. Rev Assoc Méd Bras. 2010;56(2):227-9. 
11. Sokka T, Kautiainen H, Toloza S, et al. QUEST-RA: quantitative clinical assessment of patients with rheumatoid arthritis seen in standard rheumatology carein 15 countries. Ann Rheum Dis. 2007;66(11):1491-6.

12. Putrick P, Sokka T, Ramiro $S$, et al. Impact of socioeconomic gradients within and between countries on health of patients with rheumatoid arthritis (RA): lessons from QUEST-RA. Best Pract Res Clin Rheumatol. 2012;26:705-20.

13. Chung CP, Sokka T, Arbogast PG, Pincus T. Work disability in early rheumatoid arthritis: higher rates but better clinical status in Finland compared with the US. Ann Rheum Dis. 2006;65(12):1653-7.

14. Verstappen SM, Jacobs JW, Hyrich KL. Effect of anti-tumor necrosis factor on work disability. J Rheumatol 2007; 34(11): 2126-2128.

15. Wee MM, Lems WF, Usan $H$, et al. The effect of biological agents on work participation in rheumatoid arthritis patients: a systematic review. Ann Rheum Dis. 2012;71(2):161-71.

16. Sokka T, Envalds M, Pincus T. Treatment of rheumatoid arthritis: a global perspective on the use of antirheumatic drugs. Mod Rheumatol. 2008;18(3): 228-39.

17. Biliavska I, Stamm TA, Martinez-Avila J, et al. Application of the 2010 ACR/ EULAR classification criteria in patients with very early inflammatory arthritis: analysis of sensitivity, specificity and predictive values in the SAVE studycohort. Ann Rheum Dis. 2013;72:1335-41.

18. Hifinger M, Norton S, Ramiro S, et al. Equivalence in the health assessment questionnaire (HAQ) acrosssocio-demographic determinants: analyses within QUEST-RA. Semin Arthritis Rheum. 2018;47(4):492-500.

19. Aletaha D, Smolen J, Ward MM. Measuring function in rheumatoid arthritis: identifying reversible and irreversible components. Arthritis Rheum. 2006;54: 2784.

\section{Publisher's Note}

Springer Nature remains neutral with regard to jurisdictional claims in published maps and institutional affiliations.

Ready to submit your research? Choose BMC and benefit from:

- fast, convenient online submission

- thorough peer review by experienced researchers in your field

- rapid publication on acceptance

- support for research data, including large and complex data types

- gold Open Access which fosters wider collaboration and increased citations

- maximum visibility for your research: over $100 \mathrm{M}$ website views per year

At BMC, research is always in progress.

Learn more biomedcentral.com/submissions 